\title{
Extreme emissions from shallow water methane seepages Zelenka (Northern Bulgarian Black Sea region) before earthquake Md 4.7 August 5, 2009
}

\section{Екстремни емисии от плитки метанови извори Зеленка (Българско Северно Черноморие), предшествали земетресението Md 4.7 на 5 август 2009 г.}

\author{
Petar Petsinski', Atanas Vasilev ${ }^{1}$, Konstantin Gerilowski', Violeta Slabakova ${ }^{1}$, Emil Botev ${ }^{3}$, \\ Milen Tsekov ${ }^{4}$, Orlin Dimitrov ${ }^{1}$, Nikolai Dobrev ${ }^{5}$, Dimitar Parlichev ${ }^{1}$ \\ Петьр Пецински ${ }^{1}$, Атанас Василев ${ }^{1}$, Константин Гериловски ${ }^{2}$, Виолета Слабакова ${ }^{1}$, \\ Емил Ботев $^{3}$, Милен Цеков ${ }^{4}$, Орлин Димитров $^{1}$, Николай Добрев $^{5}$, Димитър Пърличев ${ }^{1}$

\footnotetext{
${ }^{1}$ Institute of Oceanology, Bulgarian Academy of Sciences, Varna, Bulgaria; E-mail: p.petsinski@io-bas.bg

${ }^{2}$ Institute of Environmental Physics, University of Bremen, Bremen, Germany; E-mail: gerilows@iup.physik.uni-bremen.de

${ }^{3}$ National Institute of Geophysics, Geodesy and Geography - Bulgarian Academy of Sciences, Sofia, Bulgaria;

E-mail: ebotev@geophys.bas.bg

${ }^{4}$ Physical Faculty, Sofia University, Sofia, Bulgaria; E-mail: tsekov@phys.uni-sofia.bg

${ }^{5}$ Geological Institute - Bulgarian Academy of Sciences, Sofia, Bulgaria; E-mail: nddobrev62@gmail.com
}

\begin{abstract}
Aim of this work is to show evidences for pre-earthquake processes and to set up earthquake forecasting experiments, based on two hypotheses: 1) extreme change of the activity of underwater methane seeps appears days before earthquakes; 2) effects from increase of shallow water seeps emissions are visible on satellite images.
\end{abstract}

Keywords: earthquakes, methane, gas seepages, satellite images, forecasting.

\section{Въведение}

Изследванията за прогнозиране на земетресения включват изучаване на разнообразни параметри: ниво на радон (Sabbarese et al., 2020); ниво на подпочвени води (Nakagawa et al., 2019); вариации на електромагнитно поле (Florios et al., 2020); топлинно излъчване (Wei et al., 2019); дълги вълни (Xiong, Shen, 2017); йоносферни ефекти (Kelley et al., 2017) и др. Основна пречка на изброените подходи пред разработването на прогностични методи е ниското отношение сигнал/шум.

Ние предлагаме изучаване на активността на плитководни газови извори за целите на прогнозиране на силни земетресения. Подводните газови извори са разположени в зоната на активни разломи и най-бърз свидетел за нарастващите напрежения и деформации в района е промяната на тяхната активност. Основен газ е метанът, който е и един от най-подвижните газове в морски седименти и разломи. Активността на плитки газови извори може да бъде изучавана с дистанционни методи по създаваните аномалии на морската повърхност. Екстремални емисии биха увличали фини седименти от морското дъно, които морските течения да трансформират в контрастни струи, видими от голямо разстояние.

Перспективността на изследване на активността на подводни газови извори за целите на прогнозирането на земетресения се определя от 2 хипотези:

1) екстремални промени в активността на метанови извори настьпва дни преди значими земетресения;

2) ефектите от (1) са видими на сателитни изображения.

\section{Материали и методи}

Използваните материали включват:

1. Данни от Националната сеизмична мрежа на България за 199 земетресения в района Шабла-Балчик $\left(43.0^{\circ}-44.3^{\circ} \mathrm{N}, 27.75^{\circ}-30.0^{\circ} \mathrm{E}\right)$ за периода 1986-2014 г. Данни за най-силното земетресение в района за този период $-27.5 \mathrm{~km}$ източно от метанови извори Зеленка (в района на нос Калиакра): $43.38^{\circ} \mathrm{N}, 28.77^{\circ} \mathrm{E}$; дълбочина 
8 km; Md 4.7; 5 август 2009, 07:49:00.3 (Tsekov et al., 2019);

2. Данни от Global CMT (https://www.globalcmt. org; errors from CMT inversion): $43.42 \pm 0.02^{\circ} \mathrm{N}$, $28.60 \pm 0.02^{\circ} \mathrm{E}$; depth: $19.9 \pm 1.6$; half duration: 0.7; centroid time minus hypocenter time: 1.5 ; moment tensor: $\mathrm{Expo}=23,0.169,2.850,-3.020,-1.650$, $0.354,1.230 ; \mathrm{Mw}=5.0, \mathrm{Mb}=4.7, \mathrm{Ms}=0.0$, Scalar Moment $=3.59 \mathrm{e}+23$; Fault plane 1: strike $=211$, $\operatorname{dip}=65$, slip $=171$; Fault plane 2: strike $=305$, dip $=82$, slip $=26$ (200908050749A BLACK SEA);

3. Геофизични и геохимични данни от подводните метанови извори Зеленка (43.381 ${ }^{\circ}$ $\left.43.383^{\circ} \mathrm{N}, 28.426^{\circ}-28.431^{\circ} \mathrm{E} ; \sim 350 \times 200 \mathrm{~m}\right)$, които включват (фиг. 1a):

- ехолотна батиметрия и мозайка-изображение на морското дъно от локатор за страничен обзор с честота $800 \mathrm{kHz}$

- основни разломи в района: изворите Зеленка попадат в разломна зона Чаракман, а земетресението M4.7 - на Батовски разлом и Калиакренско-Източнотракийски линеамент; двата разлома се пресичат от Калиакренската разломна зона;

- координати на 102 най-активни групи от подводни газови извори - доказателство за добри пътища за газова миграция;

- три видеозаписа и фотографии на дълбочини $9,4,8,9$ и $6,8 \mathrm{~m}$ на най-активните подводни извори и на обширна площ около тях с микрократери на морското дъно, но без газови мехури над тях, резултат от скорошна екстремална активност (фиг. 1б, в);

- мозайка от инфрачервена камера за термоанализ FLIR, заснета от клифа, показваща температурна аномалия на морската повърхност над подводните газови извори;

- резултати от химически анализи на газа и седиментни проби.
4. Aqua EOS спьтникови изображения с разделителна способност $250 \mathrm{~m}$ от датчик MODIS true color R $(700 \mathrm{~nm}), \mathrm{G}(546.1 \mathrm{~nm}), \mathrm{B}(435.8 \mathrm{~nm})$, показващи разпространението на светла струя от изворите Зеленка;

5. Данни от Copernicus: "Black Sea high resolution L4 sea surface temperature" (30.07-11.08. 2009);

6. Метеорологични данни (30.07-11.08.2009).

Основните приложени методи включват: а) геофизична обработка на данни; б) георефериране на спьтникови изображения; в) оценка на скоростите на течения; г) оценки от метеоданни за значителни височини на вълните и критични дълбочини на нарушаване на утайките на морското дъно, доказващи, че неактивните микрократери са от 5 август 2009 г.; д) създаване на инфрачервена мозайка, определяне на температурната аномалия от подводните метанови извори и решаване на обратна геотермична задача за определяне на дълбочината и формата на топлинния източник.

\section{Резултати и заключение}

За изминалия век абисалната част на Черноморския басейн е асеизмична, но с приближаване към бреговата зона и особено в южната и западната част, сеизмичната активност се засилва (Vassilev et al., 2006), като дълбочината на хипоцентрите е 10-35 км. Известни са земетресения и крайбрежни свлачища, а съществуват и исторически сведения за цунами (Bryant, 2018), както и геолого-геофизични данни за изригване на кални вулкани. Високата степен на риск в региона изисква целенасочено изучаване на природата и ефектите от неблагоприятни и катастрофални явления.

Високата геодинамична активност на региона се доказва и от известните $\sim 50$ полигона

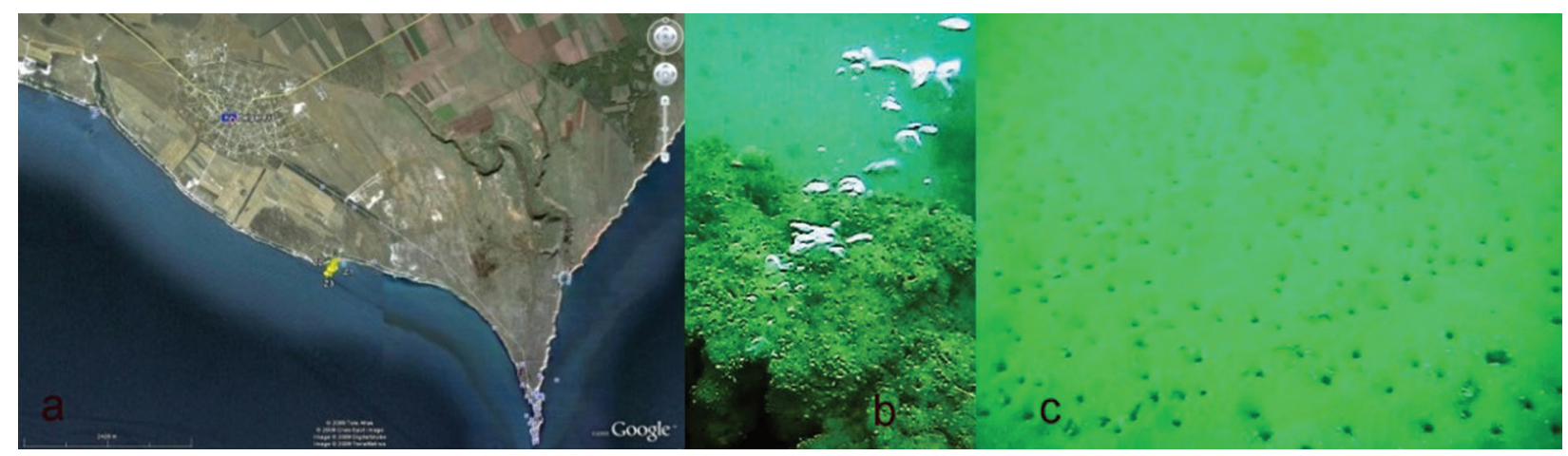

Фиг. 1. $a$ - карта на района на нос Калиакра и местоположението на метанови извори Зеленка (Google Earth, earth.google. com/web/); подводни снимки от 10.09.2009, 36 дни след земетресение М 4.7 (фото Гериловски); 6 - газови извори на морското дъно; в - неактивни микрократери 
с подводни, предимно метанови газови извори (Dimitrov, 2002), привързани към активни разломи. Първото документирано наблюдение (Palii et al., 1951) е от Аладжа банка. Други области са: Царево, Росен (Mandev et al., 1978), Камчия, Русалка, Шабла и Тюленово (Dimitrov et al., 1979).

Приведените доказателства показват, че 4 дни преди офшорното земетресение M4.7 от 5 август 2009, активността и площта на зоната с метанови извори в района на Зеленка, разположена на 27,5 km от епицентьра, се увеличава 3-5 пъти. Екстремалните емисии, фините тини от морското дъно и теченията създават контрастна струя на морската повърхност с начало в подводните газови извори, регистрирана на спътникови изображения с ниска разделителна способност - размер на пиксел $250 \mathrm{~m}$.

Морското земетресение M4.7 е предшествано от три форшока (2 и 4 август 2009 г.) и последвано от редица вторични трусове, 5 от които в периода 5-8 август 2009 г. Екстремалните емисии са предшествали с един ден групата от 9 земетресения, включваща M4.7.

Благодарности: Изследването е финансирано от ФНИ проект КП-06-ОПР 04/7 от 18.12.2018 ГЕОХидрат „Геотермична еволюция на морски находища на газови хидрати - палеоделтата на Дунав, Черно море“; ФНИ проект ДН14/1 от 11.12.2017 ГЕОАПРЕК „Изменения в геофизични полета, предшестващи земетресения в района на Балканите“; Национална научна програма „Опазване на околната среда и намаляване на рисковете от неблагоприятни събития и природни бедствия“, одобрена с Решение на Министерския съвет № 577/17.08.2018 и подкрепена от МОН (Споразумение Д01-322/18.12.2019).

\section{Литература \\ References}

Bryant, E. 2018. Tsunami: The Underrated Hazard. Berlin, Heidelberg, Springer Verlag, $330 \mathrm{p}$.

Wei, C., X. Lu, Y. Zhang, Y. Guo, Y. Wang. 2019. A timefrequency analysis of the thermal radiation background anomalies caused by large earthquakes: A case study of the Wenchuan 8.0 earthquake. - Adv. Space Res., 65, 435-445.

Dimitrov, L. 2002. Contribution to atmospheric methane by natural seepages on the Bulgarian continental shelf. - Cont. Shelf Res., 22, 16, 2429-2442.

Dimitrov, P., V. Dachev, H. Niklov, D. Parlichev. 1979. Natural gas seepages in the offshore area of Balchik Bay. Oceanology, 4, 43-49 (in Bulgarian with French abstract).

Florios, K., I. Contopoulos, V. Christofilakis. 2020. Pre-seismic electromagnetic perturbations in two earthquakes in Northern Greece. - Pure Appl. Geophys., 177, 787-799.

Kelley, M, W. Swartz, K. Heki. 2017. Apparent ionospheric total electron content variations prior to major earthquakes due to electric fields created by tectonic stresses. - J. Geoph. Res., Space Phys., 122, 6, 6689-6695.

Mandev, P., K. Markova, V. Kakacheva. 1978. Oil and gas manifestations along the Black Sea coast in the Burgas region. - J. Petrol. Coal Geol., 8, 3-23 (in Bulgarian).

Nakagawa, K., Z.-Q. Yu, R. Berndtsson, M. Kagabu. 2019. Analysis of earthquake-induced groundwater level change using self-organizing maps. - Env. Earth Sci., 78, 15, 445-455.

Palii, A., S. Gelev, K. Yankov. 1951. Geological Framework and Oil and Gas Perspectives of the Varna Region. Open Field Work Report. Sofia, National Geofond, Ministry of Energetics, 117 p. (in Bulgarian).

Sabbarese, C., F. Ambrosino, G. Chiodini, F. Giudicepietro, G. Macedonio. 2020. Continuous radon monitoring during seven years of volcanic unrest at Campi Flegrei caldera (Italy). - Sci. Rep., 10, 1, 1-10.

Tsekov, M., E. Botev, L. Dimova, R. Raykova. 2019. Seismicity of the Shabla-Kaliakra-Balchik region over the period 1986-2014. - In: EAGE 10th Con. Balkan Geoph. Soc., $1-5$.

Vassilev, A., E. Botev, R. Hristova. 2006. Dvurechenskii mud volcano, Black Sea: Long term activity from sedimentation, seismicity and tsunami data. - C. R. Acad. Bulg., 59, 11, 1181-1186.

Xiong, P., X. Shen. 2017. Outgoing longwave radiation anomalies analysis associated with different types of seismic activity. - Adv. Space Res., 59, 5, 1408-1415. 